\title{
Theoretical Study on the Mechanisms of Catalytic Hydration of Diiodine Trioxide in Marine Regions
}

\author{
Yan Liang ${ }^{1}$, Xiuhui Zhang ${ }^{1, *}$, and Wenguo $\mathrm{Xu}^{1, *}$ \\ ${ }^{1}$ School of Chemistry and Chemical Engineering, Beijing Institute of Technology, Beijing 100081, China.
}

\begin{abstract}
Diiodine trioxide $\left(\mathrm{I}_{2} \mathrm{O}_{3}\right)$ is one of the most common iodine oxides in the marine boundary layer (MBL). Both theoretical and experimental studies have confirmed that they can be quickly formed and are relatively stable under dry conditions. However, there is no report on the field observation of $\mathrm{I}_{2} \mathrm{O}_{3}$, which means that $\mathrm{I}_{2} \mathrm{O}_{3}$ is likely to be lost in the actual marine atmosphere. But the specific loss pathways and mechanisms are still unclear. Considering that the humidity in the marine regions is generally high and the loss of $\mathrm{I}_{2} \mathrm{O}_{3}$ will be affected by some substances in the marine atmosphere, water $\left(\mathrm{H}_{2} \mathrm{O}, \mathbf{W}\right)$ and iodic acid $\left(\mathrm{HIO}_{3}, \mathbf{I A}\right)$ were selected as a catalyst to investigate the catalytic hydration mechanisms of $\mathrm{I}_{2} \mathrm{O}_{3}$ at DLPNO$\operatorname{CCSD}(\mathrm{T}) / / \omega \mathrm{B} 97 \mathrm{X}-\mathrm{D} /$ aug-cc-pVTZ + aug-cc-pVTZ -PP (for iodine) level of theory. The results show that hydration of $\mathrm{I}_{2} \mathrm{O}_{3}$ presents a high energy barrier, but $\mathbf{I A}$ can reduce it to $3.76 \mathrm{kcal} / \mathrm{mol}$. Therefore, in the marine atmosphere, $\mathrm{I}_{2} \mathrm{O}_{3}$ can be hydrolyzed under the catalysis of IA, and cannot directly participate in the new particle formation process.
\end{abstract}

\section{Introduction}

Atmospheric aerosols have great impacts on human health and the atmospheric environment ([1]). Ultrafine aerosols (particle matter with a size of less than $2.5 \mu \mathrm{m}$ ) are key components of local and regional air pollution. There is increasing evidence that exposure to ultrafine aerosols can cause some acute and chronic diseases ([2]). In addition, aerosols can also affect the cloud formation process by increasing the total amount of cloud condensation nuclei $(\mathrm{CNN})$, which in turn has an important impact on the climate ([3]). Marine covers $71 \%$ of the total surface of the earth, thus, marine aerosols have a non-negligible position in the global aerosol system. In recent years, the outbreaks of ultrafine particles have been frequently observed in marine areas ([4-7]). Researchers have confirmed that the formation of new particles in the marine regions is linked to the iodine-containing substances in the marine atmosphere.

Diiodine trioxide $\left(\mathrm{I}_{2} \mathrm{O}_{3}\right)$ is a common iodine oxide in the marine boundary layer (MBL) ([8]). A laboratory study has shown that the polymerization between IO and OIO radicals will generate $\mathrm{I}_{2} \mathrm{O}_{3}$ ([9]). Lifetime calculation showed that the time for $\mathrm{I}_{2} \mathrm{O}_{3}$ to resist pyrolysis is $1.67 \times 10^{11} \mathrm{~s}([10])$, indicating that $\mathrm{I}_{2} \mathrm{O}_{3}$ can therefore remain in the marine atmosphere for a certain period. However, so far, there is no report on the field observation of $\mathrm{I}_{2} \mathrm{O}_{3}$, which means that $\mathrm{I}_{2} \mathrm{O}_{3}$ is likely to be lost due to certain reactions in the actual marine atmosphere. But the specific loss pathways and mechanisms are still unclear, which greatly affects people's understanding of the biogeochemical cycle of iodine. Considering that the humidity in the marine regions is generally high and the loss of $\mathrm{I}_{2} \mathrm{O}_{3}$ will be affected by some substances in the marine atmosphere, it is speculated that $\mathrm{I}_{2} \mathrm{O}_{3}$ may be hydrolyzed in the gas phase. Thus, common substances in the marine atmosphere, water $\left(\mathrm{H}_{2} \mathrm{O}, \mathbf{W}\right)$ and iodic acid $\left(\mathrm{HIO}_{3}, \mathbf{I A}\right)$, were selected as a catalyst to investigate the catalytic hydration reaction mechanisms of $\mathrm{I}_{2} \mathrm{O}_{3}$.

In the present paper, the hydrations of $\mathrm{I}_{2} \mathrm{O}_{3}$ without catalyst and catalyzed by $\mathbf{W}$ as well as IA were studied

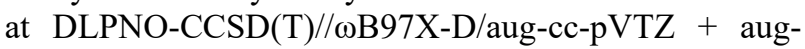
cc-pVTZ-PP level of theory to explore whether hydration is one of the loss pathways of $\mathrm{I}_{2} \mathrm{O}_{3}$.

\section{Methods}

The method of quantum chemistry calculation is used to study the hydration reactions of $\mathrm{I}_{2} \mathrm{O}_{3}$ when common substances $\mathbf{W}$ and IA in the marine atmosphere act as catalysts. The configurations of the stationary points and transition states are optimized by using the Gaussian-09 ([11]) software package at $298 \mathrm{~K}$ and 1 atm. All calculations are performed at DLPNO-

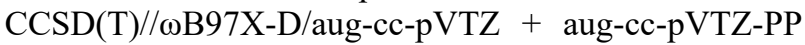
level of theory ([12]). The aug-cc-pVTZ-PP basis set with effective core potential ECP28MDF $([13,14])$ is used for the iodine atom and the conventional aug-ccpVTZ ([15]) basis set for the other atoms. And intrinsic reaction coordinate (IRC) calculations were performed to ensure the translation states were correctly connected to the corresponding reactants and products. And the Gibbs free energies $(G)$ of compounds were calculated as:

$$
G=E_{\mathrm{SPE}}+G_{\text {thermal }}
$$

\footnotetext{
* Corresponding author: zhangxiuhui@bit.edu.cn, xuwg60@bit.edu.cn
} 
where $E_{\mathrm{SPE}}$ is the single-point energy calculated by the DLPNO-CCSD(T) method, and $G_{\text {thermal }}$ is the thermal corrections to Gibbs free energy calculated by the $\omega$ B97X-D method.

In order to predict the reaction sites of $\mathrm{I}_{2} \mathrm{O}_{3}$ hydration, Multiwfn 3.6 ([16]) and Visual Molecular Dynamics (VMD) ([17]) software were also used to analyze the electrostatic potential (ESP) ([18]) on the molecular surface and draw ESP-mapped of molecular van der Waals (vdW) surfaces of reactants.

\section{Results and discussion}

\subsection{The hydration of $\mathrm{I}_{2} \mathrm{O}_{3}$ without catalysts}

In order to explore the reaction sites of $\mathrm{I}_{2} \mathrm{O}_{3}$ hydration, the electrostatic potential (ESP) on the surfaces of $\mathrm{I}_{2} \mathrm{O}_{3}$ and $\mathbf{W}$ molecules was first analyzed. As shown in Fig. 1, the two hydrogen atoms of $\mathbf{W}$ have a relatively positive electrostatic potential (red area), and the two oxygen atoms of $\mathrm{I}_{2} \mathrm{O}_{3}$ have a relatively negative electrostatic potential (blue area). Therefore, the complex $\mathrm{I}_{2} \mathrm{O}_{3}-\mathrm{H}_{2} \mathrm{O}$ $\left(\mathbf{I}_{2} \mathrm{O}_{3}-\mathbf{W}\right)$ can be formed through electrostatic attraction between $\mathbf{W}$ and $\mathrm{I}_{2} \mathrm{O}_{3}$.

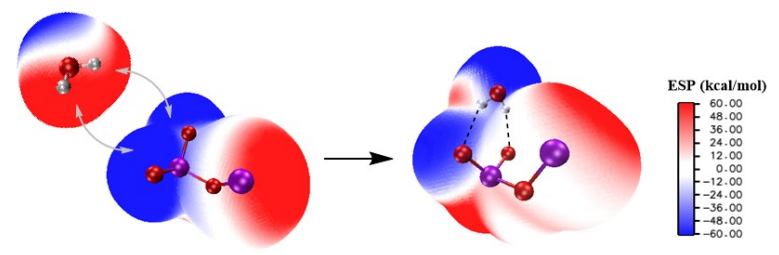

Fig. 1. The ESP-mapped molecular vdW surfaces of reactants $\mathrm{I}_{2} \mathrm{O}_{3}$ and $\mathbf{W}$ as well as the pre-reaction complex $\mathbf{I}_{2} \mathrm{O}_{3}-\mathbf{W}$. The purple, red, and grey spheres represent $\mathbf{I}, \mathbf{O}$, and $\mathbf{H}$ atoms, respectively. The black and grey dashed line refers to the hydrogen bond between $\mathrm{I}_{2} \mathrm{O}_{3}$ and $\mathbf{W}$, respectively.

Subsequently, the $\mathrm{I}_{2} \mathrm{O}_{3}$ hydration reaction was

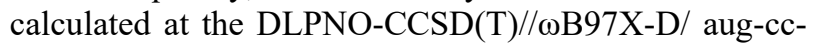
pVTZ (H, C, N, O, S) + aug-cc-pVTZ-PP (for iodine) level of theory. Take the sum of Gibbs free energies $(G)$ of the reactants as the zero point of the potential energy surface. Fig. 2 (a) is the potential energy surface of the $\mathrm{I}_{2} \mathrm{O}_{3}$ hydration reaction, and Fig. 2 (b) is the corresponding energy profile. The hydration of $\mathrm{I}_{2} \mathrm{O}_{3}$ starts with the collision between $\mathrm{I}_{2} \mathrm{O}_{3}$ and $\mathbf{W}$ molecules to form the pre-reaction complex $\mathbf{I}_{2} \mathrm{O}_{3}-\mathbf{W}$ with a relative Gibbs free energy of $4.31 \mathrm{kcal} / \mathrm{mol}$. Then, $\mathbf{I}_{2} \mathbf{O}_{3}-\mathbf{W}$ overcomes a relatively high Gibbs free energy barrier of $32.60 \mathrm{kcal} / \mathrm{mol}$ to generate the product $\mathrm{HIO}_{3}$-HOI (IAHA). The energy barrier of the reaction is as high as $32.60 \mathrm{kcal} / \mathrm{mol}$, and it is an endothermic reaction, indicating that without the participation of catalysts, the hydration reaction of $\mathrm{I}_{2} \mathrm{O}_{3}$ is difficult to occur in the actual marine atmosphere.

On this basis, the mechanism of $\mathrm{I}_{2} \mathrm{O}_{3}$ hydration was further analyzed. As shown in Fig. 2 (a), a proton of $\mathbf{W}$ transfers to the $\mathbf{O}$ atom of $\mathrm{I}_{2} \mathrm{O}_{3}$ while the $\mathbf{O H}$ moiety binds to the $\mathbf{I}$ atom of $\mathrm{I}_{2} \mathrm{O}_{3}$ to form the product. Therefore, the nature of the $\mathrm{I}_{2} \mathrm{O}_{3}$ hydration is the transfer of a hydrogen proton. (a)

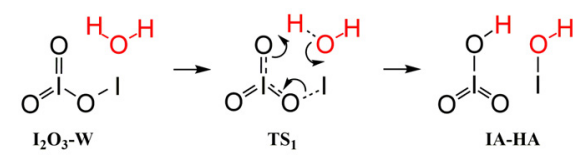

(b)

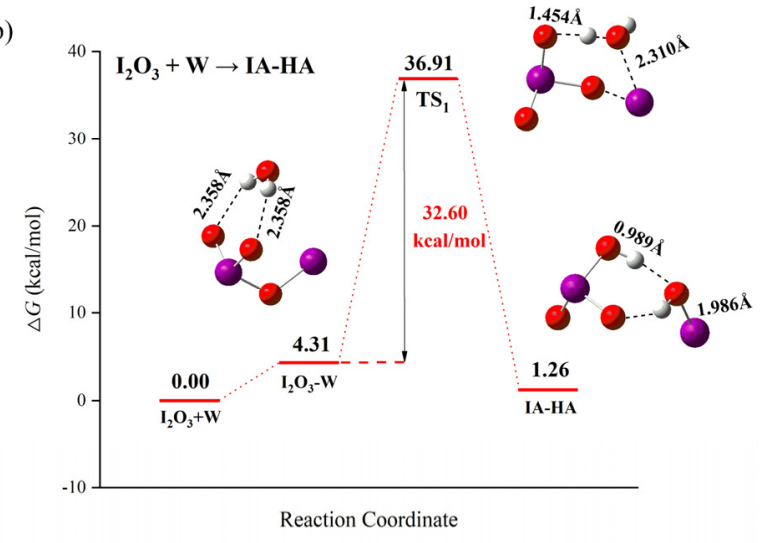

Fig. 2. (a) Reaction mechanism for the gas-phase hydration of $\mathrm{I}_{2} \mathrm{O}_{3}$ with no catalyst. (b) Potential energy profiles ( $\mathrm{kcal} / \mathrm{mol}$ ) for gas-phase hydration of $\mathrm{I}_{2} \mathrm{O}_{3}$ with no catalyst calculated at

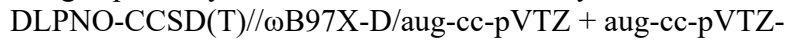
PP (for iodine) level of theory at $298 \mathrm{~K}$ and $1 \mathrm{~atm}$. The purple, red, and white spheres represent $\mathrm{I}, \mathrm{O}$, and $\mathrm{H}$ atoms, respectively.

\subsection{The hydration of $\mathrm{I}_{2} \mathrm{O}_{3}$ catalyzed by $\mathrm{W}$}

The marine atmosphere is very humid, so the concentration of $\mathbf{W}$ is generally high. $\mathbf{W}$ can act as a proton acceptor and donor at the same time, thereby accelerating the transfer of protons between molecules, so $\mathbf{W}$ may be used as a catalyst. In this section, the hydration reaction of $\mathrm{I}_{2} \mathrm{O}_{3}$ when $\mathbf{W}$ acts as a catalyst was studied. Fig. 3 (a) shows the $\mathrm{I}_{2} \mathrm{O}_{3}$ hydration mechanism catalyzed by $\mathbf{W}$, and Fig. 3 (b) shows the potential energy surface of the corresponding reaction.

As shown in Fig. 3 (b), the catalytic hydration of $\mathrm{I}_{2} \mathrm{O}_{3}$ has two pathways: $\mathrm{I}_{2} \mathrm{O}_{3}$ first collides with $\mathbf{W}$ to form $\mathbf{I}_{2} \mathrm{O}_{3}-\mathbf{W}$ and two $\mathbf{W}$ molecules collide first to form $\mathbf{W}-\mathbf{W}$ dimer. The pathway that first forms the $\mathbf{W}-\mathbf{W}$ dimer requires the lowest energy and is the main pathway. Then, $\mathbf{W}-\mathbf{W}$ collides with $\mathrm{I}_{2} \mathrm{O}_{3}$ to form the prereaction complex $\mathbf{I}_{2} \mathrm{O}_{3}-\mathbf{W}-\mathbf{W}$, and $\mathbf{I}_{2} \mathrm{O}_{3}-\mathbf{W}-\mathbf{W}$ overcomes a relatively Gibbs free energy barrier of $16.91 \mathrm{kcal} / \mathrm{mol}$ to generate the product $\mathrm{HIO}_{3}-\mathrm{HOI}-\mathrm{H}_{2} \mathrm{O}$ (IA-HA-W). The catalytic reaction is endothermic and there is a certain energy barrier. Therefore, when $\mathbf{W}$ acts as a catalyst, the hydration reaction of $\mathrm{I}_{2} \mathrm{O}_{3}$ is unfavorable in both kinetics and thermodynamics.

It is worth noting that, compared with the reaction of $\mathrm{I}_{2} \mathrm{O}_{3}$ without a catalyst, $\mathbf{W}$ as a catalyst effectively reduces the energy barrier from $32.60 \mathrm{kcal} / \mathrm{mol}$ to 16.91 $\mathrm{kcal} / \mathrm{mol}$. This is because, with the participation of the catalyst $\mathbf{W}$, the transition state changes from the original six-membered ring structure to an eight-membered ring structure, and the ring strain of the transition state is therefore reduced, so the energy barrier becomes lower. When $\mathbf{W}$ acts as a catalyst, it assists the transfer of protons between molecules by accepting and donating protons simultaneously. In summary, $\mathbf{W}$ as a catalyst 
assists the transfer of protons between molecules, thereby lowering the energy barrier.

(a)
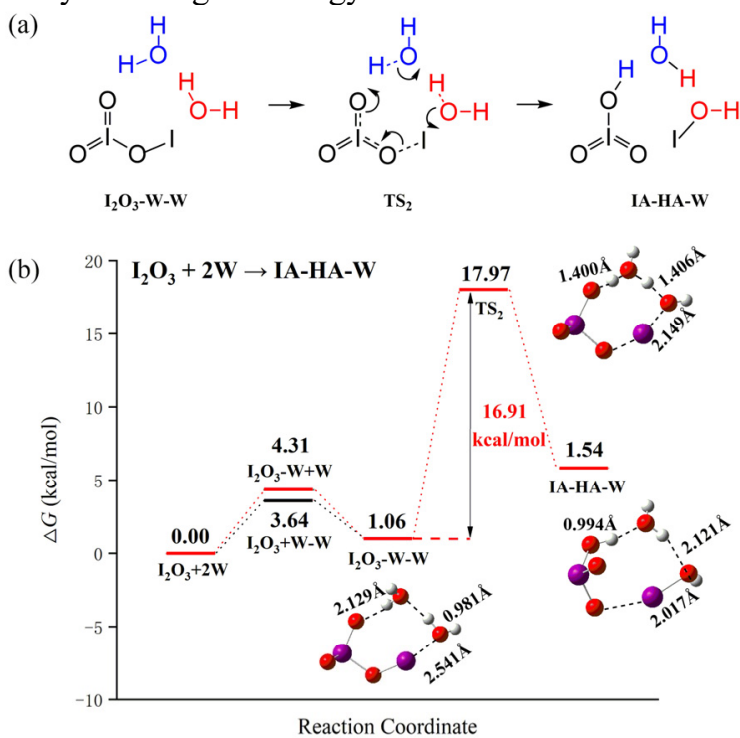

Fig. 3. (a) Reaction mechanism for the gas-phase hydration of $\mathrm{I}_{2} \mathrm{O}_{3}$ catalyzed by $\mathbf{W}$. (b) Potential energy profiles ( $\left.\mathrm{kcal} / \mathrm{mol}\right)$ for gas-phase hydration of $\mathrm{I}_{2} \mathrm{O}_{3}$ catalyzed by $\mathbf{W}$ calculated at

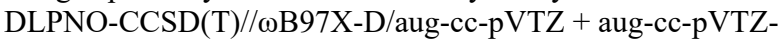
PP (for iodine) level of theory at $298 \mathrm{~K}$ and $1 \mathrm{~atm}$. The purple, red, and white spheres represent $\mathrm{I}, \mathrm{O}$, and $\mathrm{H}$ atoms, respectively.

\subsection{The hydration of $\mathrm{I}_{2} \mathrm{O}_{3}$ catalyzed by IA}

As discussed above, the nature of the $\mathrm{I}_{2} \mathrm{O}_{3}$ hydration is the transfer of protons between $\mathrm{I}_{2} \mathrm{O}_{3}$ and $\mathbf{W}$. As one of the hydration products of $\mathrm{I}_{2} \mathrm{O}_{3}, \mathbf{I A}$ is very common in marine atmosphere and has a relatively high concentration ([21]), and it can act as both an acceptor and a donor of protons. Thus, it is necessary to study whether IA can catalyze the hydration of $\mathrm{I}_{2} \mathrm{O}_{3}$ by assisting the transfer of protons. Fig. 3 (a) shows the $\mathrm{I}_{2} \mathrm{O}_{3}$ hydration mechanism catalyzed by IA, and Fig. 3 (b) shows the potential energy surface of the corresponding reaction.

There are three different bi-molecular collision modes between $\mathrm{I}_{2} \mathrm{O}_{3}, \mathbf{I A}$, and $\mathbf{W}\left(\mathbf{I}_{2} \mathrm{O}_{3}-\mathbf{W}, \mathbf{I}_{2} \mathrm{O}_{3}-\mathbf{I A}\right.$, and IA-W) so there are three pathways for the catalytic reaction. The formation of $\mathbf{I}_{2} \mathrm{O}_{3}-\mathbf{W}$ and $\mathbf{I}_{2} \mathrm{O}_{3}-\mathbf{I A}$ is endothermic, so these two pathways are not likely to occur in the actual marine atmosphere. The pathway that first forms the IA-W is exothermic, thus it is the main pathway. And IA-W collides with $\mathrm{I}_{2} \mathrm{O}_{3}$ to form prereaction complex $\mathbf{I}_{2} \mathbf{O}_{3}-\mathbf{I A}-\mathbf{W}$, which then forms (IA) 2 HA by a stepwise mechanism. This reaction has a very low energy barrier $(3.76 \mathrm{kcal} / \mathrm{mol})$ and is exothermic, so it is kinetically and thermodynamically favorable. In addition, the energy released by the formation of the reaction complex $\mathbf{I}_{2} \mathrm{O}_{3}-\mathbf{I A - W}$ is higher than the energy barrier, so the reaction can occur spontaneously in the common marine atmosphere. It should be noted that the Gibbs free energy of the Intermediate (Int) is slightly higher than that of Transition State 2 ( $\mathbf{T S}_{2}$ ) because of the calculation error, which is caused by the approximate electron density used in the DFT calculations, and it always occurs in systems involving proton transfer $([18,19])$.

As shown in Fig. 4 (a), the participation of the catalyst IA changed the transition state into a tenmembered ring structure, which further reduces the ring strain of the transition states and makes the reaction energy barrier lower $(3.76 \mathrm{kcal} / \mathrm{mol})$. The specific catalytic mechanism is that IA first gives a proton to $\mathrm{I}_{2} \mathrm{O}_{3}$, thus, forming the intermediate (Int) $\mathrm{HIO}_{3}-\mathrm{IH}_{2} \mathrm{O}^{+}$$\mathrm{IO}_{3}{ }^{-}$, and then $\mathrm{IO}_{3}{ }^{-}$accepts the proton from $\mathbf{W}$ to form the product (IA) 2 -HA. The mechanisms of IA catalytic and $\mathbf{W}$ catalytic are similar, the $\mathbf{I A}$ and $\mathbf{W}$ both assist the transfer of protons between $\mathrm{I}_{2} \mathrm{O}_{3}$ and $\mathbf{W}$ by accepting and donating protons. The difference is that when IA acts as a catalyst, the transfer of protons is step by step, but the transfer of protons is simultaneous when $\mathbf{W}$ acts as a catalyst. Compared with W, IA is a stronger proton donor and is easier to give protons, so the energy barrier is lower than when $\mathbf{W}$ catalyzing.

(a)

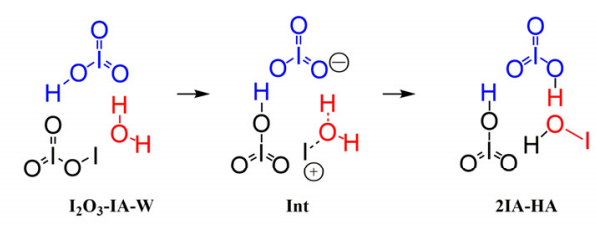

(b)

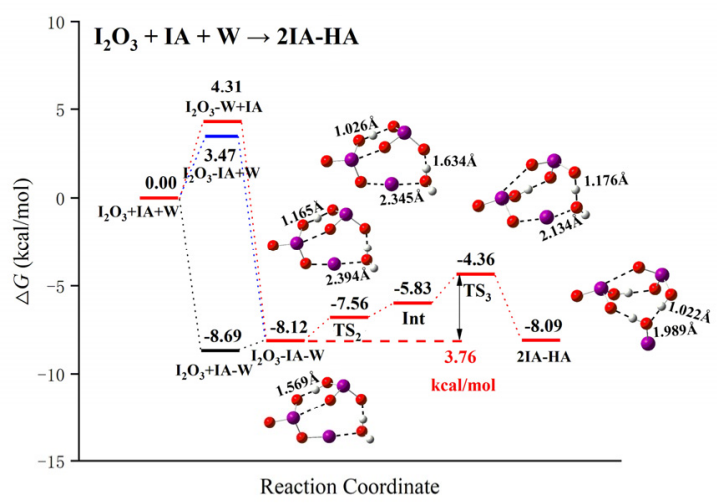

Fig. 4. (a) Reaction mechanism for the gas-phase hydration of $\mathrm{I}_{2} \mathrm{O}_{3}$ catalyzed by IA. (b) Potential energy profiles ( $\left.\mathrm{kcal} / \mathrm{mol}\right)$ for gas-phase hydration of $\mathrm{I}_{2} \mathrm{O}_{3}$ catalyzed by $\mathbf{I A}$ calculated at

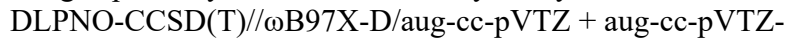
$\mathrm{PP}$ (for iodine) level of theory at $298 \mathrm{~K}$ and 1 atm. The purple, red, and white spheres represent I, O, and $\mathrm{H}$ atoms, respectively.

\section{Conclusions}

The gas-phase hydrations of $\mathrm{I}_{2} \mathrm{O}_{3}$ with no catalyst and with common atmospheric substances $\mathbf{W}$ and $\mathbf{I A}$ as

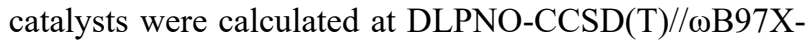
D/aug-cc-pVTZ + aug-cc-pVTZ-PP (for iodine) level of theory. The results showed that under the catalysis of $\mathbf{W}$ and IA, the energy barrier is reduced. Especially under the catalysis of $\mathbf{I A}$, the energy barrier can be reduced to $3.76 \mathrm{kcal} / \mathrm{mol}$, and the catalytic reaction spontaneously occurred. IA is both one of the products of the $\mathrm{I}_{2} \mathrm{O}_{3}$ hydration reaction and a catalyst, so the reaction can be autocatalyzed. The concentration of IA gradually 
increases as the reaction proceeds, so the role of $\mathbf{I A}$ in the $\mathrm{I}_{2} \mathrm{O}_{3}$ hydration gradually increases. Thus, $\mathrm{I}_{2} \mathrm{O}_{3}$ is unstable and short-lived, and much likely to undergo hydration to generate IA in the marine regions, which is one of the loss pathways of $\mathrm{I}_{2} \mathrm{O}_{3} . \mathrm{I}_{2} \mathrm{O}_{3}$ cannot directly participate in the formation of new particles in the marine atmosphere, but the products IA may be involved in the nucleation process, therefore catalytic hydration reaction may trigger the formation of new particles.

This research can provide a comprehensive understanding of the biogeochemical cycle of iodine and provide theoretical guidance for the formation of new particles in marine and coastal regions.

\section{References}

1. Murphy D.M. Ravishankara A.R. Trends and patterns in the contributions to cumulative radiative forcing from different regions of the world. Proc Natl Acad Sci U S A. 115,52 (2018)

2. Gong J.C. Zhu T. Kipen H. et al. Comparisons of Ultrafine and Fine Particles in Their Associations with Biomarkers Reflecting Physiological Pathways. Environ Sci Technol. 48, 9 (2014)

3. Glasow R. Seaweed, Iodine, New Particles and Atmospheric Chemistry - The Current State of Play. Environ Chem. 2, 4 (2005)

4. Dall'Osto M. Simo R. Harrison R.M. et al. Abiotic and biotic sources influencing spring new particle formation in North East Greenland. Atmos Environ. 190 (2018).

5. McFiggans G. Coe H. Burgess R. et al. Direct evidence for coastal iodine particles from Laminaria macroalgae - linkage to emissions of molecular iodine. Atmos Chem Phys. 4 (2004)

6. Jimenez J.L Bahreini R. Cocker III D.R. et al. New particle formation from photooxidation of diiodomethane $\left(\mathrm{CH}_{2} \mathrm{I}_{2}\right)$. J Geophys Res. 108, D10 (2003)

7. Saiz-Lopez A. Plane J.M.C. Novel iodine chemistry in the marine boundary layer. Geophys Res Lett. 31, 4 (2004)

8. Saiz-Lopez A. Plane J.M. Baker A.R. et al. Atmospheric Chemistry of Iodine. Chem Rev. 112, 3 (2012)
9. Galvez O. Gomez Martin J.C. Gomez P.C. et al. A theoretical study on the formation of iodine oxide aggregates and monohydrates. Phys Chem Chem Phys. 15, 3 (2013)

10. Gomez Martin J.C. Galvez O. Baeza-Romero M.T. et al. On the mechanism of iodine oxide particle formation. Phys Chem Chem Phys. 15, 37 (2013)

11. Frisch M.J. Trucks G.W. Schlegel H.B. et al. Gaussian 09, Revision A.1, Gaussian, Inc. Wallingford, CT. (2009)

12. Peterson K.A. Systematically Convergent Basis Sets with Relativistic Pseudopotentials. I. Correlation Consistent Basis Sets for the Post-D Group 13-15 Elements. J Chem Phys. 119, 21 (2003)

13. Feller D. The role of databases in support of computational chemistry calculations. J Comput Chem. 17, 13 (1996)

14. Schuchardt K.L. Didier B.T. Elsethagen T. et al. Basis set exchange: a community database for computational sciences. J Chem Inf Model. 47, 3 (2007)

15. Peterson K.A. Systematically Convergent Basis Sets with Relativistic Pseudopotentials. I. Correlation Consistent Basis Sets for the Post-D Group 13-15 Elements. J Chem Phys. 119, 21 (2003)

16. Lu T. Chen F. Multiwfn: a multifunctional wavefunction analyzer. J Comput Chem, 33, 5 (2012)

17. Humphrey W. Dalke A. Schulten K. VMD: visual molecular dynamics. J Mol Graph. 14, 1 (1996)

18. Mohan N. Suresh C.H. A molecular electrostatic potential analysis of hydrogen, halogen, and dihydrogen bonds. J Phys Chem A. 118, 9 (2014)

19. You Z.S.; Guo C. Pan Y.J. An experimental and theoretical study on fragmentation of protonated N(2-pyridinylmethyl) indole in electrospray ionization mass spectrometry. Rapid Commun Mass Spectrom. 26, (2012)

20. Kim M.C. Sim E. Burke K. Understanding and reducing errors in density functional calculations. Phys Rev Lett. 111,7 (2013)

21. Sipila M. Sarnela N. Jokinen T. et al. Molecularscale evidence of aerosol particle formation via sequential addition of $\mathrm{HIO}_{3}$. Nature. 537, 7621 (2016) 